\title{
Antimicrobial Activity of Biosynthesized Silver Nanoparticles against E. coli and B. subtilis
}

Salwa Al-Thawadi*, Alaa Shukralla A. Rasool and Khaled Youssef

Department of Biology, University of Bahrain, Sakhir, Kingdom of Bahrain

\begin{abstract}
Silver nanoparticles (AgNPs) are used increasingly in medical and agricultural sectors for disease management, due to their antimicrobial activity. In the current study, Biosynthesized AgNPs produced from a previous study (AgNPs1, AgNPs2 and AgNPs3) were used to test their toxicity on gram negative ( $E$. coli) and gram positive (B. subtilis) bacteria. These nanoparticles (NPs) were examined by scanning electron microscopy (SEM), energy dispersive X-ray analysis (EDS) and X-ray diffraction (XRD). SEM micrographs show that AgNPs1 were almost spherical monodispersed while AgNPs2 were aggregated. More aggregations appeared in AgNPs3. Peaks of AgNPs are obvious in the EDS which were confirmed further by XRD peaks ascertaining the precipitation of AgNPs. Toxicity effect of AgNPs was tested by exposing E. coli and B. subtilis to AgNPs1, AgNPs2 and AgNPs3 during their growth. Bacterial growth was followed by OD at $600 \mathrm{~nm}$. Unexpectedly, an enhancement effect was proven in the presence of AgNPs1 for both bacterial strains, whereas an inhibition effect of bacterial growth was proven in the presence of AgNPs2 and AgNPs3. AgNPs3 were selected to test their minimum toxicity effect against E. coli and $B$. subtilis which shown to be $10 \mathrm{mg} . \mathrm{L}^{-1}$. To our knowledge, this study was the first study to show bacterial growth enhancement effect for AgNPs. The reasons for this enhancement need further investigation.
\end{abstract}

Keywords: Toxicity; Silver nanoparticles; Bacteria; E. coli; B. subtilis

\section{Introduction}

Biosynthesis of metallic silver NPs (AgNPs) are attracting attention due to the positive environmental impact of using microorganisms in the production of nanoparticles (NPs). This synthesis of AgNPs is a low cost process, time saving approach and the biosynthesized NPs are highly stable [1,2]. Physiochemical properties of NPs include size, shape, surface area, surface charge, aggregation, topography, crystallinity, elemental composition, zeta potential and photocatalytic properties $[3,4]$. In addition, lots of physiochemical properties and metabolic activity are associated with AgNPs due to their large surface area to volume ratio [5]. These unique properties of AgNPs enable them to be used for sensing and imaging applications, medical biosensors, diagnosis, drug delivery, medical device coating and antimicrobial agent. Due to the antimicrobial activity of AgNPs, remarkable advances in agricultural and medical sectors could be approached effectively for plant and human disease management as bio pesticides and antibiotic agents respectively [6,7].

AntimicrobialpropertiesofAgNPsarewelldocumentedandrepresent a promising approach for developing new antimicrobial systems [8]. They are used to protect drinking water from pathogens or prevent microbial derived bad odors [9]. AgNPs were shown to be the most toxic NPs especially to crustaceans and algae [10]. Their toxicity (AgNPs, $10 \mathrm{~nm}$ ) could affect the mammalian cells e.g. human lung cells [11]. In medical sector, AgNPs are increasingly used due to their surface to volume ratio in addition to other properties. Previously, heavy metal ions including silver ions were used for their microbial toxicity via reduction of the metal ions or formation of metal sulfides [12]. After the development in AgNPs production, the nanoparticles were used instead of the metal ion owing to their powerful toxicity effect $[10,13,14]$. The increase in the use of AgNPs in different sectors raised a concern due to their occasional release the environment [9]. Studying the toxicity of AgNPs, is an important area of research owing to its potential application in the fight against multi-drug resistant microorganisms.

Toxicity mechanism for AgNPs against living organisms is still unclear. Lots of studies proven that AgNPs penetrate different living cells $[13,14]$. Therefore, the action of those NPs is inside the cells and not at cellular surface. AgNPs exhibit microbial toxicity via the release of Ag+ ions which subsequently penetrate into bacterial cells [14]. McShan et al. [15] showed one of the toxicity mechanism which is oxidative stress via reactive oxygen species (ROS) generation, damaging cell membrane and other cell components including DNA, depleting antioxidant molecules (e.g., glutathione), disabling proteins, lowering reductase activity, reducing protein expression and depressing the activity of some membranous enzymes. Another study showed that apoptosis of E. coli increased with the increase in AgNPs concentrations (5 or 10 $\mu \mathrm{g} / \mathrm{ml}$ ) of 5-10 $\mathrm{nm}$ size [13] in addition to the interaction of both silver ionic and AgNPs form with sulfurcontaining macromolecules such as proteins, due to the strong affinity of silver for sulfur [15].

Due to the development in AgNPs application in the medical sector, examining their potential biological toxicity is becoming necessary. Therefore, this study was done to examine the toxicity effect of different biosynthesized AgNPs against E. coli and B. subtilis in addition to the determination of their minimum toxic concentration. The authors selected those particular test strains because they are the best characterized model organisms for gram negative and gram positive bacteria $[14,16]$.

\section{Materials and Methods}

\section{The growth of AgNPs producing bacteria}

Bacterial strain which synthesizes AgNPs (Bacillus sp.) was isolated in a previous study [1] and preserved in 15\% sterile glycerol. The glycerol

*Corresponding author: Salwa Al-Thawadi, Department of Biology, University of Bahrain, Sakhir, Kingdom of Bahrain, Tel: +973-17437557; E-mail: salwaalthawadi@gmail.com; salthawadi@uob.edu.bh

Received November 30, 2017; Accepted December 19, 2017; Published December 26, 2017

Citation: Al-Thawadi S, Rasool ASA, Youssef K (2017) Antimicrobial Activity of Biosynthesized Silver Nanoparticles against E. coli and B. subtilis. J Bioanal Biomed 9: 299-305. doi:10.4172/1948-593X.1000197

Copyright: ( $) 2017$ Al-Thawadi S, et al. This is an open-access article distributed under the terms of the Creative Commons Attribution License, which permits unrestricted use, distribution, and reproduction in any medium, provided the original author and source are credited. 
preserved bacterial cells were grown in $100 \mathrm{ml}$ of a growth medium (10 mg.L $\mathrm{L}^{-1}$ Yeast extract (YE), $10 \mathrm{mM} \mathrm{AgNO}, 152 \mathrm{mM}$ ammonium sulphate and $100 \mathrm{mM}$ sodium acetate) in $250 \mathrm{ml}$ shaking flasks at $35^{\circ} \mathrm{C}$, for $72 \mathrm{~h}$. The $\mathrm{pH}$ was adjusted to be 5.5 .

\section{Measuring the activity of AgNPs producing bacteria}

Silver NPs precipitation by Bacteria: The bacterial culture was mixed with the precursor $\mathrm{AgNO}_{3}$ to a final concentration of $50 \mathrm{mM}$. Immediately, one drop of this mix was placed on a microscopic slide then covered with a coverslip. The edges of the coverslip were sealed with nail polish to avoid the dryness of the sample. Crystals formation was examined (at 0 and $24 \mathrm{~h}$ ) by a compound microscope (BX51) fitted with a DP70 Digital Camera.

UV-vis spectrophotometer examination of AgNPs precipitation: To measure the activity of AgNPs precipitating bacteria, bacterial culture $(3 \mathrm{ml})$ grown on $100 \mathrm{mM} \mathrm{AgNO}$ for three days was examined by UV-vis spectrophotometer (Spectronic Unicam). The experiment was repeated three times against a control sample, in which the test strains were grown in the absence of $\mathrm{AgNO}_{3}$.

\section{The production of AgNPs when AgNPs synthesised bacterial isolates were grown on different concentrations of $\mathrm{AgNO}_{3}$}

Bacillus sp. cells were grown on different concentrations of $\mathrm{AgNO}$ ( $5 \mathrm{~m} \mathrm{M}, 40 \mathrm{mM}$ and $160 \mathrm{mM}$ ) according to the same procedures and growth medium described previously in [1]. The produced NPs were named as AgNPs1, AgNPs2 and AgNPs3 which were produced when the bacteria were grown on $5 \mathrm{mM}, 40 \mathrm{mM}$ and $160 \mathrm{mM} \mathrm{AgNO}_{3}$ respectively. Each sample ( $3 \mathrm{ml}$ ) was examined by UV-vis spectroscopy (350-600 nm). Prior to measuring the OD, the samples were mixed well to avoid the precipitation of AgNPs. For accurate readings, the samples with high concentrations of AgNPs were diluted 2-3 times to be detected by UV-vis spectroscopy. Three Replicates were applied.

\section{SEM and XRD examinations of AgNPs precipitation}

The bacterial suspension $(10 \mathrm{ml})$ was centrifuged and washed with water three times, followed by $97 \%$ alcohol to kill the bacteria. The AgNPs were dried in a desiccator for one week. These dried NPs were placed on aluminium stubs using "Carbon Tabs" (Agar Scientific). The stubs were then were dried by vacuum, followed by SEM examination (SEM-Zeiss EVO LS 10, at Central Labs of University of Bahrain). Energy Dispersive X-ray (EDS) Microanalysis of AgNPs was carried out using micro-analyser (EDS Bruker AXS Microanalyzer).

Dried AgNPs1, AgNPs2 and AgNPs3 samples were analyzed by powder X-ray diffraction (XRD) using a Rigaku Ultima-IV diffractometer equipped with $\mathrm{Cu} \alpha$-radiation $(\lambda=1.5418 \AA$ ) from $2 \theta$ $=30^{\circ}$ up $80^{\circ}$, with step size of $0.04^{\circ}$, voltage of $40 \mathrm{kV}$, current of $40 \mathrm{~mA}$, power of $1.6 \mathrm{~kW}$ and counting time of 1.0 seconds.

\section{Toxicity Effect of biologically produced AgNPs on E. coli and B. subtilis}

Two different test strains (gram negative: E. coli and gram positive: B. subtilis) were cultured into two separated sterilized nutrient broth (NB, Oxoid). The cultures were placed in a water bath shaker and allowed to grow overnight. AgNPs1, AgNPs2 and AgNPs3 (0.03 mg) were added separately to $150 \mathrm{ml} \mathrm{NB}$ in $250 \mathrm{ml}$ flasks. Next day, E. coli (2 $\mathrm{ml}$ ) culture was added to $150 \mathrm{ml} \mathrm{NB}$ mixed with AgNPs. The bacterial cultures were grown against a control in the absence of AgNPs (i.e. in the control experiment similar previous procedures were followed except the addition of $\mathrm{AgNPs}$ ), at $37^{\circ} \mathrm{C}$ for $24 \mathrm{~h}$ in a shaker incubator. The experiment was repeated three times. The same previous procedures were followed for the gram positive B. subtilis.

Optical density at $600 \mathrm{~nm}$ was measured by spectrophotometer (Thermo Scientific) for 6 hours in an interval time of 1.5-2 h. Final readings were taken after $24 \mathrm{~h}$ of the bacterial incubation.

\section{The minimum inhibition concentration effect of biologically} produced AgNPs on $E$. coli and B. subtilis growth

To study the minimum inhibition concentration effect of AgNPs produced by Bacillus sp., the test strains were grown on different concentrations of AgNPs3 (i.e. AgNPs produced when NPs synthesized bacteria were grown on $160 \mathrm{mM} \mathrm{AgNO}$ ). AgNPs3 were selected for this test because it exhibited a clear bacterial inhibition in the toxicity test. To perform the minimum inhibition test, the same procedures described above were followed except that AgNPs3 were the only type of NPs used in the test. The different concentrations of AgNPs (10$200 \mathrm{mg} . \mathrm{L}^{-1}$ ) were added to $150 \mathrm{ml} \mathrm{NB}$ against control samples. All the experiments were repeated three times.

\section{Results and Discussion}

\section{AgNPs precipitation}

Bacterial producing AgNPs (Bacillus sp.) was grown on a simple selection method in the presence of $\mathrm{AgNO}_{3}$ to produce AgNPs. Biosynthesis of these NPs is a low cost, time saving approach and does not produce toxic chemicals during the biosynthesis process. It was obvious from the light microscopic images that aggregates of AgNPs were precipitated outside the bacterial cells indicating an extracellular production of AgNPs (Figure 1). The bacterial culture showed a change in colour from yellow to dark brown (Figure 2), which is a primary indicator for AgNPs production. This change in colour was confirmed by other studies such as Zaki et al., Al-Thawadi et al. and Sithara et al. $[1,17,18]$. The intensive colour of AgNPs is due to the surface plasmon resonance (SPR) resulting from their nanosize.

The synthsized AgNPs sample shows a peak at $421 \mathrm{~nm}$ via UVvis spectroscopy examination, which proves that metallic AgNPs were produced (Figure 2). This peak is another indicator for the production of AgNPs [1] which is assigned to SPR peak for AgNPs. UV-vis spectroscopy will detect the intensive colour which formed when AgNPs interact with light at certain wavelength [19]. This result was

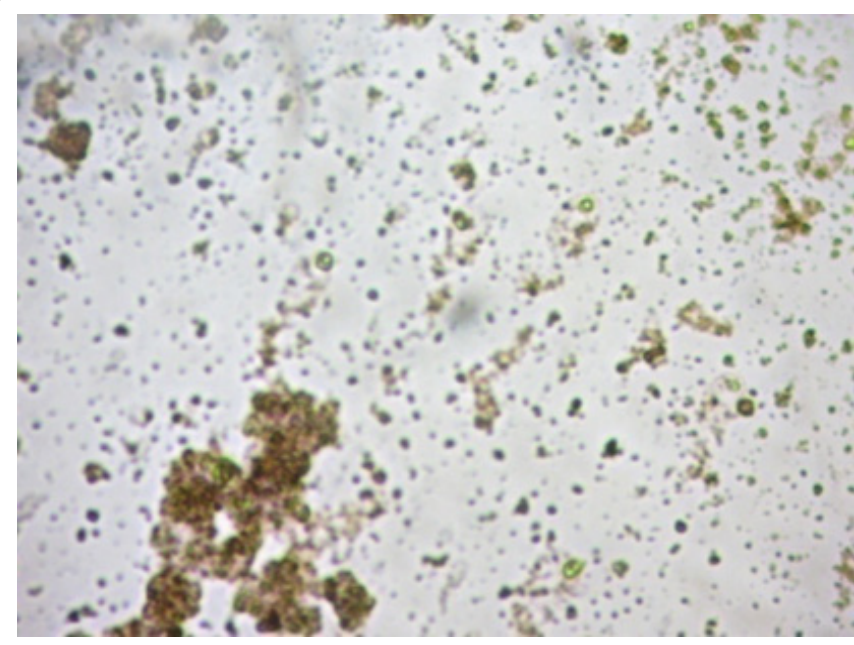

Figure 1: Precipitation of AgNPs aggregates under light microscope. 
Citation: Al-Thawadi S, Rasool ASA, Youssef K (2017) Antimicrobial Activity of Biosynthesized Silver Nanoparticles against E. coli and B. subtilis. J Bioanal Biomed 9: 299-305. doi:10.4172/1948-593X.1000197

supported by other studies aimed at producing AgNPs by aquatic weeds (Eichornia crassipes) and Klebsiella pneumonia [6,20]. Other surface Plasmon resonance peak at $440 \mathrm{~nm}$ and $390 \mathrm{~nm}$ were shown for AgNPs produced by Fusarium graminaerum and $B$. megaterium respectively

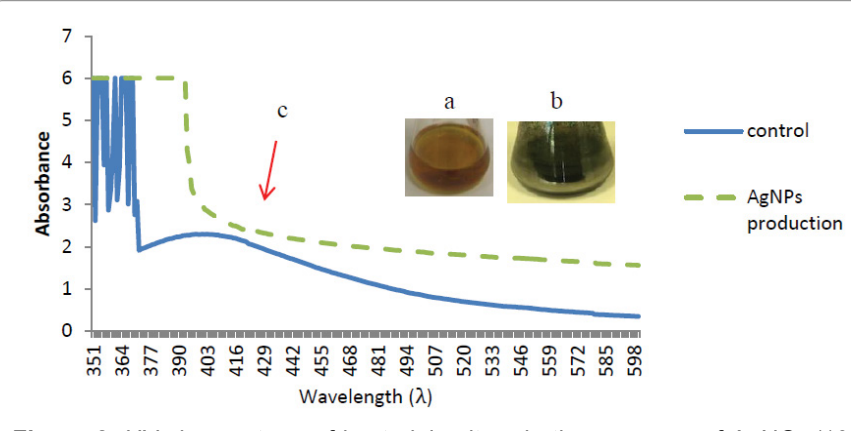

Figure 2: UV-vis spectrum of bacterial culture in the presence of $\mathrm{AgNO}_{3}(10$ $\mathrm{mM})$. Inset: The bacterial culture at 0 time $(A)$ and after $24 \mathrm{~h}(\mathrm{~B})$ in the presence of $\mathrm{AgNO}_{3}$. (C) The SPR peak of AgNPs at $421 \mathrm{~nm}$ at which the colour was changed from yellow to dark brown.
[21,22]. A broader peak at 450-480 $\mathrm{nm}$ and $420-430 \mathrm{~nm}$ were reported for chemical and biological synthesis of AgNPs respectively [15,20]. The different UV-vis spectra for growing the bacteria on different concentrations of $\mathrm{AgNO}_{3}$ were shown in a previous study [1].

\section{Examination of AgNPs1, AgNPs2 and AgNPs3 by SEM, EDS}

To confirm the structure, shape, and size of AgNPs which were produced by bacteria, SEM, EDS and XRD analyses were performed. Apparently, SEM micrographs show differences AgNPs1, AgNPs2 and AgNPs3 (Figure 3). AgNPs1 was clearly dispersed in contrary with AgNPs2 and AgNPs3 which were aggregated. So the dispersion of AgNPs1 probably has a role in the enhancement of bacterial growth while the aggregation of NPs2 and NPs3 has a role in microbial toxicity. Thus, the aggregation of NPs increased with the increase in the concentration of $\mathrm{AgNO}_{3}$ precursor in the culture medium.

SEM micrographs show shiny spots which were analysed by EDS examination (Figure 3) using backscattered electron detector (BSD, sensible to the atomic number of elements). EDS proves that those shiny spots were metallic AgNPs. The metallic AgNPs appeared
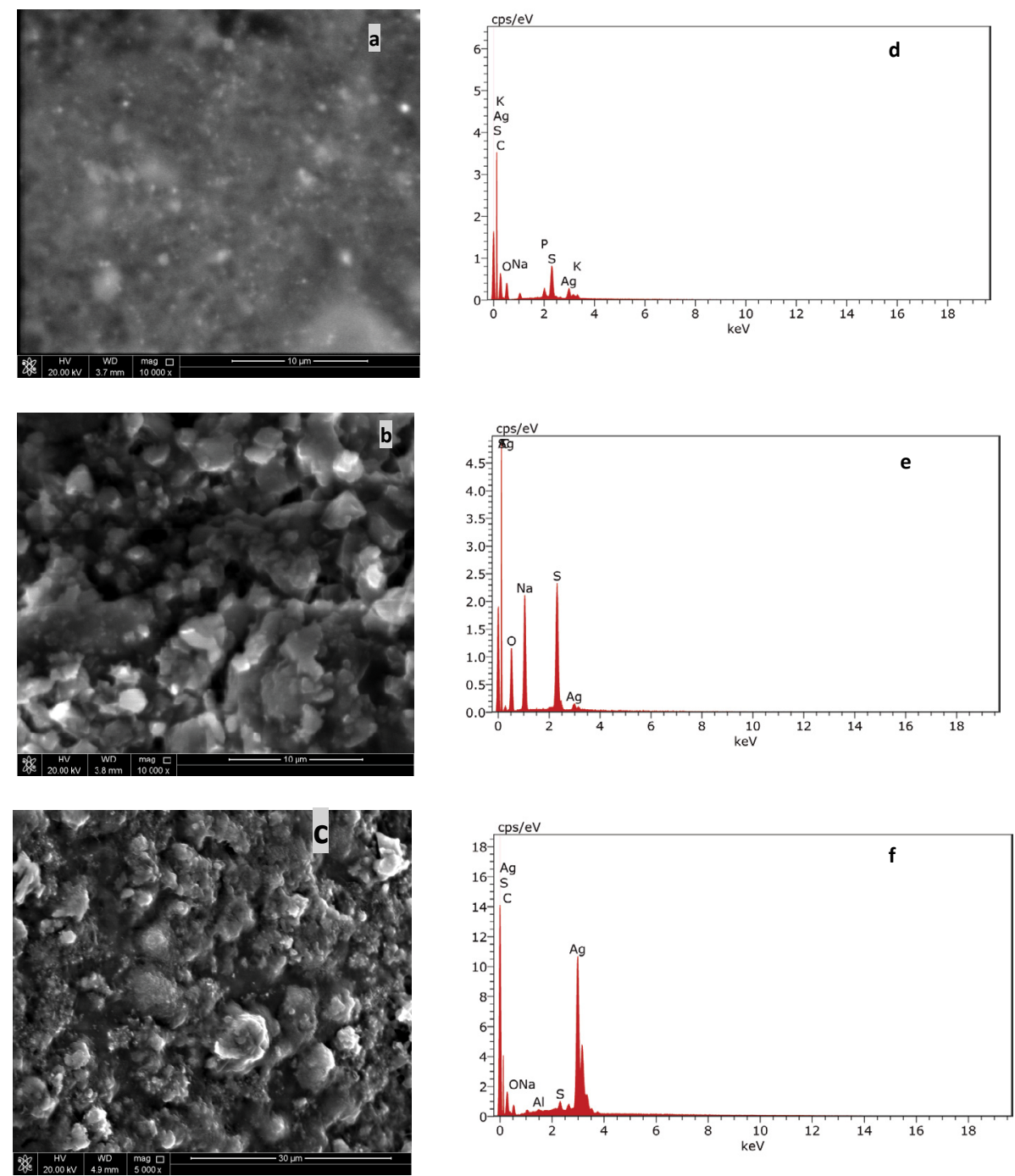

Figure 3: SEM micrographs of the bisynthesized AgNPs: (a) AgNPs1, (b) AgNPs2 and (c) AgNPs3 and their EDS analysis respectively (d-f). 
brighter in colour than the impurities (residue of media) in the sample. In addition, the micrographs showed the highest composition of silver element (Figure 3) confirming the presence of AgNPs. EDS detects other elements such as nitrogen, oxygen, potassium, sodium, sulfur and carbon. Those elements are related to the presence of the growth medium and bacterial cells in the tested sample. The synthesized AgNPs are spherical in shape.

\section{XRD examination of AgNPs1, AgNPs2 and AgNPs3}

XRD examination is an important technique for the characterization of crystal structure, determination of phase composition, detection of the presence of impurities and detection of the crystalline size of powdered NPs. The arrangement of atoms in a particular way creates a unique pattern of planes and facets that characterize the crystal structure of a material. XRD beam from the planes in specific directions and at specific angles determines the crystal structure of the material, whereas the peak shape and broadening are associated with crystallite size and micro strains. The combination of the atomic crystals of the AgNPs gives their morphological shape, which can be observed by SEM. In this study, XRD examination was applied to detect the size and structure of AgNPs1, AgNPs2 and AgNPs3 when the bacteria were grown on different concentrations of $\mathrm{AgNO}_{3}$ which are $5 \mathrm{mM}, 40 \mathrm{mM}$ and $160 \mathrm{mM}$ respectively.

XRD shows peaks of AgNPs which prove the precipitation of AgNPs. Four strong peakes resulted from XRD (Figure 4) located at $2 \theta$ values of $38.2^{\circ}, 44.4^{\circ}, 64.6^{\circ}$, and $77.6^{\circ}$. These values matched well with the cubic crystal lattice planes, (111), (200), (220) and (311) respectively of silver metal using the Joint Committee on Powder Diffraction Standards (JCPDS), data card 01-071-4613. The size of AgNPs ranges from $5 \mathrm{~nm}$ to $20 \mathrm{~nm}$. Almost, no obvious trend in the size production
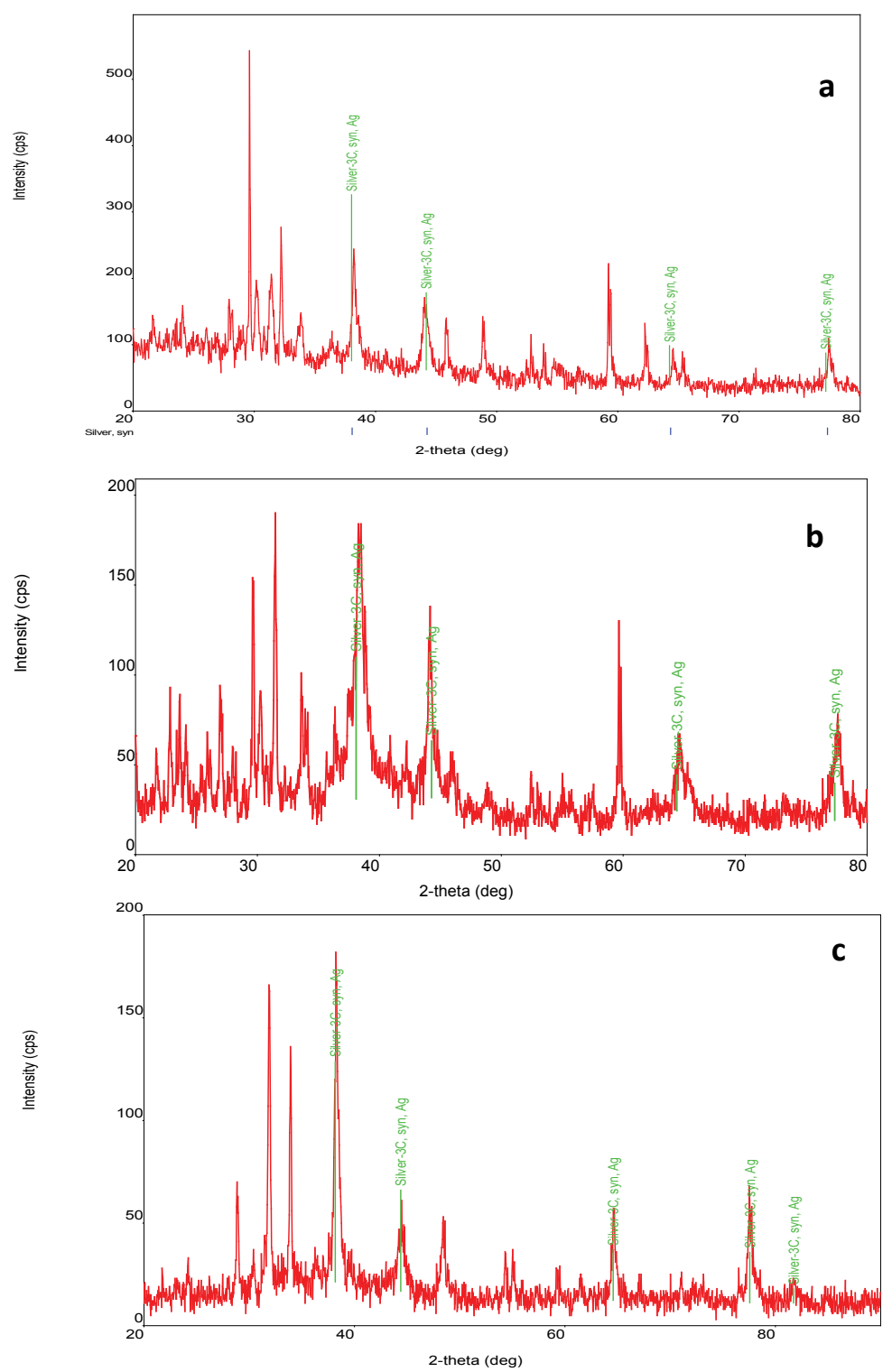

Figure 4: XRD analysis of AgNPs1, AgNPs2 and AgNPs3 deposited on a Si (III) wafer at room temperature when the bacteria were grown on (a) 5 mM, (b) 40 mM and (c) $160 \mathrm{mM}$ of $\mathrm{AgNO}_{3}$ respectively. 
of AgNPs (AgNPs1, AgNPs2 and AgNPs3) was shown. According to this result, growing the bacteria on different concentrations of the precursors $\mathrm{AgNO}_{3}$ did not affect greatly the size of the produced AgNPs.

In literature, different sizes of biosynthesized AgNPs were reported $[6,18,23]$. Averages of $20-50 \mathrm{~nm}$ AgNPs were produced by using leaf extract of Acalypha hispida [18]. Other sizes of AgNPs were recorded, For example, 50-100 nm of AgNPs were recorded to be produced by bacteria whereas AgNPs sizes of 5-55 nm were recorded to be produced by nitrate reductase extracted from the leaf of Dalbergia sisso [6,23]. The production of different sizes of AgNPs is key factors in deciding the application.

\section{Examination of the AgNPs as antibacterial agent against $E$. coli and B. subtilis}

To test the toxicity effect of the produced AgNPs at different conditions on gram negative and gram positive bacteria, similar amount of AgNPs1 (Bacillus sp. were grown on $5 \mathrm{mM} \mathrm{AgNO}_{3}$ ), AgNPs2 (Bacillus sp. were grown on $40 \mathrm{mM} \mathrm{AgNO}_{3}$ ) and AgNPs3 (Bacillus sp. were grown on $160 \mathrm{mM} \mathrm{AgNO}_{3}$ ) were added to test strains culture. Those test strains were E. coli (gram negative) and B. subtilis (gram positive). The bacterial growth of test strains was followed by OD at $600 \mathrm{~nm}$. An increase of bacterial growth was evident when AgNPs1 was added to both E. coli and B. subtilis (Figures 5 and 6). This enhancement result was an average of three replicates. The experiment was reproducible; as another experiment of three replicates was done showing an enhancement effect in the presence of AgNPs1 for both E. coli and B. subtilis growth. For the two other treatments (AgNPs2 and AgNPs3), a decrease in the OD was shown (Figures 5 and 6) proving that there is a decrease in the growth of both types of bacteria. Therefore, an inhibition effect on bacterial growth of both $E$. coli and B. subtilis was evident when using AgNPs2 and AgNPs3.

To the best of our knowledge, the current study is the first study to show a bacterial growth enhancement due to the use of AgNPs. Lots of studies provided evidences for the toxicity effect of AgNPs on both gram positive and gram negative bacteria [14,24,25]. The enhancement effect of AgNPs1 was reproducible through repeated experiments at different times of both E. coli and B. subtilis toxicity examination. Therefore, this enhancement effect cannot be a coincidence. The reason for the resulted enhancement effect from the use of AgNPs1 was unknown. They were spherical particles

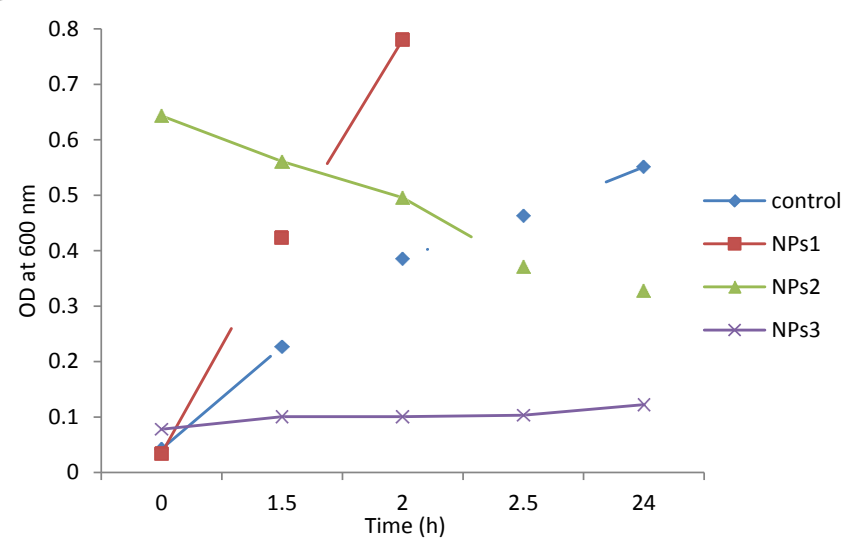

Figure 5: Toxicity effect of AgNPs1, AgNPs2 and AgNPs3 on E. coli during 6 hours incubation. similar to AgNPs2 and AgNPs3. Moreover, the sizes of these NPs were almost close to each other ranges from 5-20 nm. This size is within the range of the particles size that can penetrate the cell membrane which is proven to be from $16 \mathrm{~nm}$ to $30 \mathrm{~nm}[14,24,25]$. On the other hand, antimicrobial activity was proven to be caused by AgNPs with size of $\leq 10 \mathrm{~nm}$ [26]. So neither the size nor the shape of AgNPs caused the enhancement effect of the bacterial growth in the current study.

Several studies support the unclear understanding of particle size and shape on microbial toxicity [27]. On the contrary, it is well documented that the size and shape of AgNPs cause microbial inhibition [13,26]. Ivask et al. [26] proved that the decrease in particle nano size will increase the toxicity of Ag NPs. This is probably due to the penetration of those NPs which was evident in E. coli and $B$. subtilis supported by TEM images [14,24,25]. AgNPs (5 or $10 \mu \mathrm{g} / \mathrm{ml})$ penetration caused cellular apoptosis which increased with the increase in AgNPs concentrations [13]. A study showed that all shapes of NPs have antimicrobial effects against $E$. coli; however, the triangular shape is more effective [28]. The reason for this strong effect of the triangular shape is the formation of positive charge on the NPs, associated with the active facets on a triangular-shaped particle. Further studies should be done to explain the reason for bacterial enhancement of AgNPs1 and toxicity by both AgNPs2 and AgNPs3 to determine its exact enhancement and toxicity mechanism. Those examinations should include TEM and extracellular and intracellular enzyme in addition to TEM examination impacted by the tested NPs.

The outer-membrane of E. coli is made of tightly packed lipopolysaccharide (LPS) molecules that provide an effective permeability barrier. It was found that AgNPs lead to the formation of unusual-shaped pits in the outer-membrane changing its permeability [28]. In addition, AgNPs reduce the activity of lactate dehydrogenase (LDH) enzyme which is important in cellular respiration via releasing ROS in E. coli [29].

Bacillus cell wall is primary composed of a thick layer (20-80 $\mathrm{nm}$ ) of peptideoglycan made of linear polysaccharide chains crosslinked by short peptide bond to form 3-D rigid structure. The rigidity and the progressive cross-linked decrease the bacteria cell wall anchoring site for AgNPs and made the wall more difficult to be penetrated [30]. AgNPs (10-50 ppm) adversely affect the cell morphology and DNA integrity of B. subtilis. In their study, Hsueh et al. [14] show proves for the morphological changes and chromosomal DNA aberration due to the treatment with AgNPs

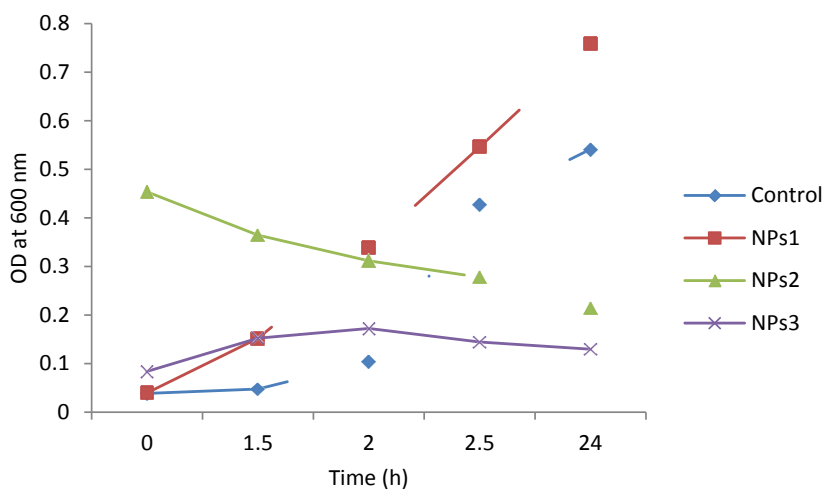

Figure 6: Toxicity effect of NPs1, NPs2 and NPs3 on B. subtilis growth during 6 hours incubation. 
$[14,31]$. In addition, their results revealed that a concentration of 25 or 50 ppm of AgNPs adversely affect Phage-GFP and cytosolic protein expression and decrease the reductase activity causing a significant increase in membrane permeability [14].

Proteomics technology was used to test the impact of AgNPs on B. thuringiensis. It was found that exposing those cells to different concentrations of AgNPs causes dissipation of a proton motive force due to the accumulation of envelope protein precursors. Those identified proteins are involved in critical processes in the cell such as oxidative stress tolerance, metal detoxification, transcription and elongation processes, protein degradation, cytoskeleton remodeling and cell division [32]. Proteomics as an emerging technology provide a critical way to understand the toxicity of AgNPs on different proteins produced in the cells. This analysis should be done to determine the enhancement effect of AgNPs1 and toxicity effect of AgNPs2 and AgNPs3 on both E. coli and B. subtilis.

In general, the toxicity of AgNPs on bacteria was studied thoroughly in lots of studies. Possible reasons for the toxicity effect was the larger surface to volume ratio, release of Ag+ from oxidative dissolution of AgNPs, damage of the cell membrane causing leakage of molecules, depress of the activity of membranous enzymes, penetration of $\mathrm{Ag}^{+}$ ions into bacterial cells, degrading of chromosomal DNA, lowering reductase activity, cause ribosomes denaturation with the inhibition of protein synthesis, binding with the genetic material blocking transcription and translation, and reducing protein expression $[14,24,28,33,34]$.

\section{Minimum concentration of AgNPs which can cause toxicity for $E$. coli and B. subtilis growth}

AgNPs3 were selected to be tested for the minimum inhibitory concentrations exerted on E. coli and B. subtilis. Different concentrations of AgNPs3 (10-200 mg. $\left.\mathrm{L}^{-1}\right)$ were used. It was found that $10 \mathrm{mg} . \mathrm{L}^{-1}$ inhibited the growth of both bacteria while $10-200 \mathrm{mg} . \mathrm{L}^{-1}$ have a lethal effect on their growth (Figures 7 and 8). Further study should be done to determine the reasons for AgNPs3 toxicity on the bacteria growth. Those examinations should include TEM and extracellular and intracellular enzymes affected by the tested NPs.

The aggregation of AgNPs1 was less than the aggregation of AgNPs2 and AgNP3. Therefore, this aggregation of AgNPs increased with the increase in the concentration of $\mathrm{AgNO}_{3}$ precursor in the culture medium. High concentrations of ion in the medium can break the electrical double layers around the AgNPs, leading to AgNPs aggregation [35]. Lots of studies confirmed that the size, aggregation and the settlements of NPs determine their effect [36]. Specifically, Moreno-Garrido et al. [37] compared the diverse effects of AgNPs on different microalgae species (marine and freshwater forms).

\section{Conclusions}

In this study the toxicity of AgNPs toward gram negative (E. coli) and gram positive (B. subtilis) bacteria was determined. These NPs were produced by bacteria through different treatments to produce AgNPs1, AgNP2 and AgNPs3. The formation of AgNPs was confirmed by the appearance of Plasmon resonance peak at $421 \mathrm{~nm}$, SEM coupled with EDS and XRD analyses. It was found that $200 \mathrm{mg} . \mathrm{L}^{-1}$ of AgNPs1 has an enhancement effect for E. coli and B. subtilis growth, while NPs2 and NPs3 exert a toxic effect on bacterial growth. For minimum inhibitory concentration of those NPs, a concentration of $10-200 \mathrm{mg} . \mathrm{L}^{-1}$ was used against both strains. It was found that $10-20 \mathrm{mg} \cdot \mathrm{L}^{-1}$ lower bacterial

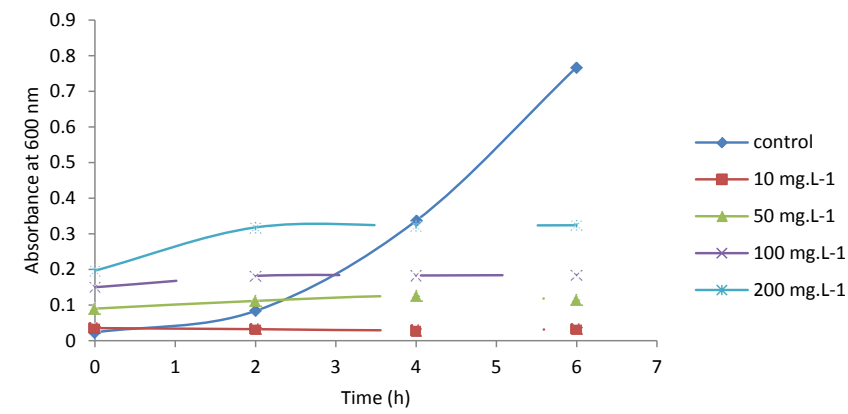

Figure 7: The effect of different concentrations of AgNPs3 (10-200 mg.L-1). They were produced when the bacteria were grown on $160 \mathrm{mM}$ the $\mathrm{AgNO}_{3}$ on E. coli growth at $37^{\circ} \mathrm{C}$ for 6 hours (b) after $24 \mathrm{~h}$. Bacterial growth inhibition was clear for a concentration as low as $10 \mathrm{mg} \cdot \mathrm{L}^{-1}$.

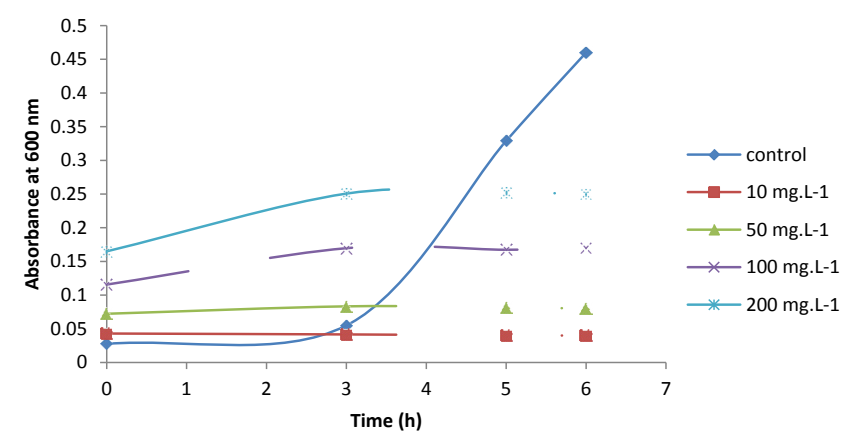

Figure 8: The effect of AgNPs3 of different concentrations AgNPs3 was produced when the bacteria were grown on $160 \mathrm{mM}$ silver nitrate on $B$. subtilis growth at $37^{\circ} \mathrm{C}$ for 6 hours. Bacterial growth inhibition was clear for a concentration as low as $10 \mathrm{mg} \cdot \mathrm{L}^{-1}$.

growth while $200 \mathrm{mg} \cdot \mathrm{L}^{-1}$ was considered as strongly toxic AgNPs. The toxicity mechanism was unclear. Further analysis should be carried out to clarify the reasons beyond this toxicity. The only clear hint given by SEM micrographs is the dispersion of AgNPs1 and the agglomeration of AgNPs2 and AgNPs3. Thus, the enhancement effect of AgNPs1 (200 $\left.\mathrm{mg} . \mathrm{L}^{-1}\right)$ probably was due to the dispersion of NPs while the toxicity effect for both AgNPs2, and AgNPs3 was due to their aggregation.

It is concluded that there is a potential use of AgNPs as an alternative to conventional antimicrobial agents at particular concentrations; alternatively, AgNPs which were prepared in a special way and at particular concentration might be used as a stimulator for the growth.

\section{Acknowledgements}

The authors would like to thank the University of Bahrain for providing the financial support to complete this research. The authors as well thank Hanan Khalifa and Ms Sakina Mustafa for their generous help in the SEM and XRD examinations.

\section{References}

1. Al-Thawadi S, Mustafa S, Bououdina M (2015) Biosynthesis of Different Sizes of Silver Nanoparticles by Bacteria Screened from Cultivated Soil. IJSR 4: 182-189.

2. Sileikaite A, Prosycevas I, Puiso J, Juraitis A, Guobiene A (2006) Analysis of silver nanoparticles produced by chemical reduction of silver salt solution. Mater Sci 12: 287-291.

3. Rao C, Biswas K (2009) Characterization of nanomaterials by physical methods. Annu Rev Analyt Chem 2: 435-462.

4. Subbenaik SC (2016) Physical and chemical nature of nanoparticles. In: Kole C, Kumar DS, Khodakovskaya (eds) Plant nanotechnology: Principles and practices. ( $\left.1^{\text {stedn }}\right)$, Springer International Publishing, Switzerland, pp: 15-27. 
Citation: Al-Thawadi S, Rasool ASA, Youssef K (2017) Antimicrobial Activity of Biosynthesized Silver Nanoparticles against E. coli and B. subtilis. J Bioanal Biomed 9: 299-305. doi:10.4172/1948-593X.1000197

5. Dakal TC, Kumar A, Majumdar RS, Vinod Y (2016) Mechanistic Basis of Antimicrobial Actions of Silver Nanoparticles. Front Microbiol. 7: 1-1716.

6. Minaeian S, Shahverdi AR, Nohi AS, Shahverdi HR (2008) Extracellular biosynthesis of silver nanoparticles by some bacteria. J Sci IAU (JSIAU) 17: 1-4.

7. Chan YS, Don MM (2012) Characterization of Ag Nanoparticles Produced by White-Rot Fungi and Its in vitro Antimicrobial. IAJAA 2: 3.

8. Ouay BL, Stellacci F (2015) Antibacterial Activity of Silver Nanoparticles: A Surface Science Insight. Nano Today 10: 339-354.

9. Dobias J, Bernier-Latmani R (2013) Silver release from silver nanoparticles in natural waters. Environ Sci Technol. 47: 4140-4146.

10. Bondarenko O, Juganson K, Ivask A, Kasemets K, Mortimer M, et al. (2013) Toxicity of $\mathrm{Ag}, \mathrm{CuO}$ and $\mathrm{ZnO}$ nanoparticles to selected environmentally relevant test organisms and mammalian cells in vitro: A critical review. Arch Toxicol 87: 1181-1200.

11. Gliga A, Skoglund S, Odnevall, Wallinder I, Fadeel B, et al. (2014) Sizedependent cytotoxicity of silver nanoparticles in human lung cells: The role of cellular uptake, agglomeration and Ag release. Part Fibre Toxicol 11: 11.

12. Argueta-Figueroa L, Martínez-Alvarezb O, Santos-Cruzc J, Garcia-Contrerasa RLS, Acosta-Torresa LS, et al. (2017) Nanomaterials made of non-toxic metallic sulfides: A systematic review of their potential biomedical applications. Mater Sci Eng:C 76: 1305-1315

13. Bao H, Yu X, Xu C, Li X, Li Z, et al. (2015) New Toxicity Mechanism of Silver Nanoparticles: Promoting Apoptosis and Inhibiting Proliferation. PLoS One 10.

14. Hsueh YH, Lin KS, Ke WJ, Hsieh CT, Chiang CL, et al. (2015) The Antimicrobial Properties of Silver Nanoparticles in Bacillus subtilis Are Mediated by Released $\mathrm{Ag}^{+}$Ions. PLoS One 15: 1-17.

15. Mlalila NG, Swai HS, Hilonga AD, Kadam M (2017) Antimicrobial Dependence of Silver Nanoparticles on Surface Plasmon Resonance Bands against Escherichia coli. Nanotechnol Sci Appl 10: 1-9.

16. McShan D, Ray PC, Yu H (2014) Molecular toxicity mechanism of Nanosilver. J Food Drug Anal 22: 116-127.

17. Zaki S, El Kady MF, Abd-El-Haleem D (2011) Biosynthesis and structura characterization of silver nanoparticles from bacterial isolates. Mater Res Bull 46: 1571-1576

18. Sithara R, Selvakumar P, Arun C, Anandan S, Sivashanmugam P (2017) Economical Synthesis of Silver Nanoparticles using Leaf Extract of Acalypha hispida and its Application in the Detection of Mn(II) ions. J Adv Res 8: 561-568.

19. Wijnhoven SWP, Peijenburg WJGM, Herbert CA, Hagens WI, Oomen Al, et al. (2009) Nano-silver- A Review of Available Data and Knowledge Gaps in Human and Environmental Risk Assessment. Nanotoxicology 3: 109-138.

20. Jeevan P, Ramya K, Rena AE (2012) Extracellular biosynthesis of silver nanoparticles by culture supernatant of $P$ seudomonas aeruginosa. IJBT 11: $72-76$.

21. Saravanan M, Vemu AK, Barik SK (2011) Rapid biosynthesis of silver nanoparticles from Bacillus megaterium (NCIM 2326) and their antibacteria activity on multi drug resistant clinical pathogens. Colloids Surf B 88: 325- 331.
22. Shafiq SA, Al-Shammari RH, Majeed HZ (2016) Study of biosynthesis silver nanoparticles by Fusarium graminaerum and test their antimicrobial activity. Intern J Innov Appl Stud 15: 43-50.

23. Boopathi S, Gopinath S, Boopathi T, Balamurugan V, Rajeshkumar R, et al. (2012) Characterization and antimicrobial properties of silver and silver oxide nanoparticles synthesized by cell-free extract of a mangrove associated Pseudomonas aeruginosa M6 using two different thermal treatments. Ind Eng Chem Res 51: 5976-5985.

24. Singh C, Baboota RK, Naik PK, Singh H (2012) Biocompatible synthesis of silver and gold nanoparticles using leaf extract of Dalbergia sissoo. Adv Mat Lett 3: $279-285$

25. Raffi M, Hussain F, Bhatti TM (2008) Antibacterial characterization of Silve Nanoparticles agsinst E. coli ATTC-15224. J Matter Sci Technol 24: 192-196.

26. Zhou G, Wang W (2012) Synthesis of silver nanoparticles and their antiproliferation against human lung cancer cells in vitro. Orien $\mathrm{J}$ Chem 28 : 651-655.

27. Nikaido H (2003) Molecular basis of bacterial outer membrane permeability revisited. Microbiol Mol Biol Rev 67: 593-656.

28. Akshi R, Chauhan R (2009). Colloidal synthesis of silver nano particles. Asian J Chem 1-4.

29. Sondi I, Salopek-Sondi B (2004) Silver nanoparticles as antimicrobial agent: A case study on E. coli as a model for Gram-negative bacteria. J Colloid Interface Sci 275: 177-182.

30. Mirzajani F, Hamzelou S, Schober Y, Rompp A (2014) Proteomics study of silver nanoparticles toxicity on Bacillus thuringiensis. Ecotox Environ Safe 100: 122-130.

31. Li WR, Xie XB, Shi QS, Zeng HY, Ou-Yang YS, et al. (2010) Antibacterial activity and mechanism of silver nanoparticles on Escherichia coli. Appl Micr Biotech 85: 1115-1122.

32. Dash A, Singh AP, Chaudhary BR, Singh SK, Dash D (2012) Effect of silver nanoparticles on growth of eukaryotic green algae. Nano-Micro Letters 4: 158-165.

33. Ivask A, Kurvet I, Kasemets K, Blinova I, Aruoja V, et al. (2014) Size-dependen toxicity of silver nanoparticles to bacteria, yeast, algae, crustaceans and mammalian cells in vitro. PLoS One 9: e102108.

34. Bai Y, Wu F, White JC, Xing B (2014)100 Nanometers: A potentially Inappropriate Threshold for Environmental and Ecological Effects of Nanoparticles. Environ Sci Technol 48: 3098-3099.

35. Yue Y, Li X, Sigg L, Suter MJF, Pillai S, et al. (2017) Interaction of silve nanoparticles with algae and fish cells: A side by side comparison. J Nanobiotechnol 15: 16.

36. Sager TM, Porter DW, Robinson VA, Lindsley WG, Schwegler-Berry DE et al. (2007) Improved method to disperse nanoparticles for in vitro and in vivo investigation of toxicity. Nanotoxicology 1.

37. Moreno-Garrido I, Pérez S, Blasco J (2015) Toxicity of silver and gold nanoparticles on marine microalgae. Mar Environ Res 111: 60-73. 